\title{
Synthesis of Polythioamides from Dithioamide and Diamine
}

\author{
Yasushi Kishimoto and Naoya OGata \\ Department of Chemistry, Sophia University, Chiyoda-ku, Tokyo, Japan.
}

(Received November 13, 1972)

\begin{abstract}
Aromatic and aliphatic dithioamides were synthesized and the polycondensation reaction with nucleophiles such as diamine, dihydrazides or diols was carried out. The polycondensation reaction of dithioisophthalamide (DTI) with hexamethylenediamine (HMD) took place in a good yield at $60^{\circ} \mathrm{C}$ to form polythioamide with elimination of ammonia. However, the polycondensation rate was found to be much slower than that of dithiocarboxylic acid-O,O-diethyl esters and it took more than a few weeks for completion of the polycondensation reaction. On the other hand, DTI did not react with dihydrazides and diols at all and the reactivity of thioamide toward nucleophiles was inferior to that of dithiocarboxylic acid-O,O-diethyl ester.

KEY WORDS Polycondensation / Polythioamide / Dithioamide /

Diamine / Dihydrazide / Diol /
\end{abstract}

It was previously reported ${ }^{1}$ that the following solution polycondensation reaction of dithiocarboxylic acid-O,O-diethyl ester with diamines proceeded at room temperature to form high molecular weight polythioamides.

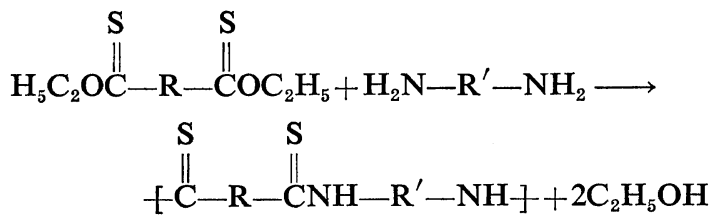

In this reaction, solvents had a great influence both on the reactivity of the monomer and on the structure of the resulting polythioamide. For instance, dimethylsulfoxide was an effective solvent for producing a linear polymer, while an insoluble polymer with a cross-linked structure was obtained in ethanol.

As reported in a previous paper, ${ }^{2}$ dithiocarboxylic acid- $O, O$-diethyl ester could also react with other weak nucleophiles such as dihydrazides or diols to form the corresponding polymers at a relatively low temperature when a suitable solvent was selected for the polycondensation.

During the synthesis of dithiocarboxylic acid esters, it was incidentally found that dithioamide reacted with diamine to form polythioamide with elimination of ammonia as shown below

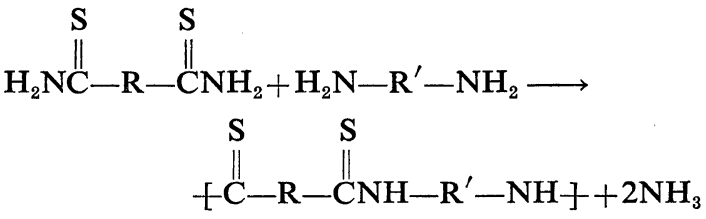

This paper deals with the polycondensation reaction of dithioamides with diamines with regard to the effect of temperature, monomer concentration, acid catalyst and solvent. The reactivity of thioamide with nucleophiles was compared with that of dithiocarboxylic acid$O, O$-diethyl ester.

\section{EXPERIMENTAL}

\section{Materials}

Commercially available reagents of first grade hexamethylenediamine, ethylenediamine, butylenediamine, $m$-phenylenediamine and $m$ xylylenediamine were distilled under reduced pressure before use. Commercial piperazine was purified by recrystallization from ethanol. $N, N^{\prime}$ Dimethyl ethylenediamine was synthesized by Shashoua's method. ${ }^{3}$ Solvents such as dimethylsulfoxide (DMSO), dimethylformamide (DMF), dimethylacetamide (DMAc), hexamethylenephosphoramide (HMPA) and $N$-methyl-2pyrrolidone (NMP) were purified by the usual procedures. Commercial polyphosphoric acid 


\section{Y. Kishimoto and N. Ogata}

(PPA) was used while polyphosphate ester (PPE) was prepared according to the method of Pollmann."

\section{Synthesis of Monomers}

Dithioadipamide was prepared by the following route: ${ }^{5}$

$$
\begin{aligned}
& \mathrm{CN}-\left(\mathrm{CH}_{2}\right)_{4}-\mathrm{CN}+2 \mathrm{CH}_{3} \mathrm{CSNH}_{2} \longrightarrow
\end{aligned}
$$

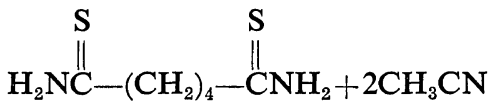

Adiponitrile $(0.5 \mathrm{~mol})$ was heated on the steam bath for $30 \mathrm{~min}$ with $2 \mathrm{~mol}$ of thioacetamide in $150 \mathrm{~m} l$ of DMF saturated with dry hydrogen chloride. Under the reduced pressure provided by a water aspirator, the reaction mixture was distilled to one-fourth of its original volume and aqueous sodium bicarbonate was added to neutralize excess acid. Thioamide was obtained by cooling the hot aqueous filtrate, followed by filtration: yield, $68 \% \mathrm{mp} 178-180^{\circ} \mathrm{C}$.

Anal. Calcd for $\mathrm{C}_{6} \mathrm{H}_{12} \mathrm{~N}_{2} \mathrm{~S}_{2}$ :

$$
\text { C, 40.87; H, 6.87; N, } 15.89 \text {. }
$$

Found: C, 40.46; H, 6.79; N, 15.92 .

Dithioisophthalamide was prepared by a modified Fairfull's method ${ }^{6}$ as shown below

$$
\text { in } \mathrm{Et}_{3} \mathrm{~N} \text { and pyridine }
$$

A $0.5 \mathrm{~mol}$ portion of isophthalonitrile was dissolved in a mixture of $200 \mathrm{~m} l$ of triethylamine and $600 \mathrm{ml}$ of pyridine as a catalyst. Dry hydrogen sulfide gas was introduced into the solution for $6 \mathrm{hr}$. Then, the solution was poured into cold water containing an excess of hydrochloric acid. The yellow precipitate was collected, washed with water, and then dissolved in ether. The ether solution was dried over anhydrous sodium sulfate. After evaporating the ether, the residure was purified by recrystallization from methanol: yield, 72.4\%; $\mathrm{mp}$ 204-207 ${ }^{\circ} \mathrm{C}$.

Anal. Calcd for $\mathrm{C}_{8} \mathrm{H}_{8} \mathrm{~N}_{2} \mathrm{~S}_{2}$ :

$$
\text { C, 48.95; H, 4.12; N, 14.27. }
$$

Found: C, 48.61; H, 4.23; N, 14.01.

\section{Solution Polycondensation}

Given amounts of dithioamide and diamine were dissolved in various solvents in the presence of $5 \mathrm{~mol} \%$ of lithium ethoxide and the solution was kept at a constant temperature under air or nitrogen atmospheres. After the polycondensation was completed, the solution was poured into water and the resulting polymers were filtered, washed with benzene, and dried.

\section{Characterization}

The characterization of polymers was done by elementary analysis and infrared spectroscopy. The solution viscosity of the polymers was measured at $30^{\circ} \mathrm{C}$ in DMSO at a concentration of $0.5 \mathrm{~g} / \mathrm{d} l$. The melting point of the polymers was measured by differential thermal analysis.

\section{RESULTS AND DISCUSSION}

\section{Polycondensation}

Table I summarizes the results for the polycondensation of dithioadipamide (DTA) or dithioisophthalamide (DTI) with hexamethylenediamine (HMD) in various solvents which were effective for the polycondensation of dithiocarboxylic acid- $O, O$-diethyl ester with diamines.

It is found in Table I that solvents such as DMSO or HMPA are effective solvent for carrying out the polycondensation reaction. However, both the yield and the solution viscosity of the resulting polythioamides are inferior to those of the polycondensation of dithioisophthalic acid- $O, O$-diethyl ester with $\mathrm{HMD}^{2}$. This latter reaction was completed within a few hours at $30^{\circ} \mathrm{C}$ to form a high-molecular-weight polythioamide in a quantitative yield. Thus it was found that the reactivity of thioamide with amine was much lower than the reactivity of $O$-thioester with amine. Also, the solvents have an influence on the structure of the obtained polymers; for instance, an insoluble polymer with a rubber-like elasticity was formed in NMP and DMSO during the reaction. The solvent effect on the polymer structure is assumed to be due to the shift of resonance form between thioamide - $\mathrm{CSNH}-$ and thiolamide $-\mathrm{C}(-\mathrm{SH})=\mathrm{N}-$. This shift might be stimulated by the basic character of NMP and DMSO.

On the other hand, the polycondensation 


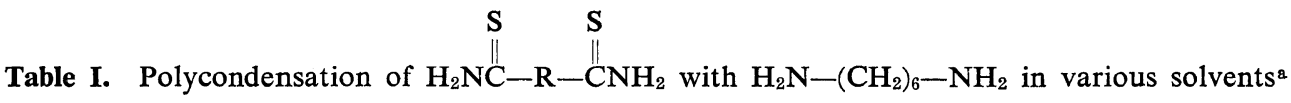

\begin{tabular}{|c|c|c|c|c|c|c|c|}
\hline \multirow{2}{*}{$\mathbf{R}$} & \multirow{2}{*}{ Atmosphere } & \multirow{2}{*}{ Solvent } & \multirow{2}{*}{ Temp, ${ }^{\circ} \mathrm{C}$} & \multirow{2}{*}{ Time, day } & \multicolumn{2}{|c|}{ Yield, \% } & \multirow{2}{*}{$\eta_{\mathrm{sp}} / c^{\mathrm{b}}$} \\
\hline & & & & & Soluble & Insoluble & \\
\hline & \multirow[t]{9}{*}{ Air } & DMF & 30 & 5 & 53.9 & 2.7 & 0.13 \\
\hline & & DMF & 60 & 10 & 57.9 & 5.2 & 0.18 \\
\hline & & DMSO & 30 & 5 & 27.4 & 2.0 & 0.12 \\
\hline & & DMSO & 60 & 5 & 63.6 & 8.3 & 0.17 \\
\hline & & DMSO & 60 & 10 & 82.6 & 10.7 & 0.23 \\
\hline & & DMAc & 60 & 10 & 63.9 & 0.9 & 0.16 \\
\hline & & HMPA & 60 & 10 & 62.3 & 3.4 & 0.25 \\
\hline & & NMP & 60 & 10 & 26.9 & 28.7 & 0.13 \\
\hline & & $m$-Cresol & 30 & 5 & 0 & - & - \\
\hline & \multirow[t]{11}{*}{ Nitrogen } & $\mathrm{DMF}$ & 30 & 5 & 30.0 & 0 & 0.12 \\
\hline & & DMF & 30 & 30 & 43.9 & 0 & 0.13 \\
\hline & & DMF & 60 & 10 & 56.2 & 0 & 0.15 \\
\hline & & DMSO & 30 & 5 & 32.6 & 0 & 0.12 \\
\hline & & DMSO & 30 & 30 & 48.6 & 0 & 0.12 \\
\hline & & DMSO & 60 & 5 & 33.0 & 0 & 0.14 \\
\hline & & DMSO & 60 & 10 & 75.5 & 0 & 0.17 \\
\hline & & DMAc & 60 & 10 & 45.7 & 0 & 0.12 \\
\hline & & HMPA & 60 & 10 & 44.3 & 0 & 0.15 \\
\hline & & NMP & 60 & 10 & 41.7 & 0 & 0.14 \\
\hline & & $m$-Cresol & 30 & 5 & 0 & - & - \\
\hline \multirow[t]{6}{*}{$-\left(\mathrm{CH}_{2}\right)_{4}-$} & \multirow[t]{3}{*}{ Air } & DMSO & 60 & 10 & 0 & 62.7 & - \\
\hline & & HMPA & 60 & 10 & 0 & 81.0 & - \\
\hline & & DMF & 60 & 10 & 0 & 65.3 & - \\
\hline & \multirow[t]{3}{*}{ Nitrogen } & DMSO & 60 & 10 & 27.6 & 0 & 0.04 \\
\hline & & HMPA & 60 & 10 & 20.1 & 0 & 0.04 \\
\hline & & DMF & 60 & 10 & 20.7 & 0 & 0.03 \\
\hline
\end{tabular}

a Monomer concn, $0.25 \mathrm{~mol} / l$; catalyst, EtOLi, $5 \mathrm{~mol} \% / \mathrm{mol}$ of monomer.

b $0.05 \mathrm{~g} / 10 \mathrm{~m} l$ in DMSO at $30^{\circ} \mathrm{C}$.

reaction under nitrogen atmosphere proceeded in a homogeneous phase, resulting in soluble polymers. However, both the yield and the solution viscosity of the resulting polymers were inferior to those under air atmosphere, which suggests that oxygen in air has a catalytic effect on this polycondensation reaction.

Table I indicates that the polycondensation reaction of DTA with HMD under air atmosphere led to the more favorable formation of an insoluble polymer than the polycondensation of DTI and HMD under nitrogen atmosphere, and the polycondensation of DTA with HMD under air atmosphere resulted in a poor yield of polymers which were soluble in DMSO.

Aromatic thioamide might be more stable than aliphatic thioamide because of the resonance stabilization of the aromatic nucleus and the resonance of aliphatic thioamide may be favorably shifted toward the thiolimide type. This thiolimide shift leads to an easy cross-linking reaction between two chains in the presence of oxygen, and may also have an accelerating effect on the polycondensation.<smiles>CN=C(S)C#CNC(C)=S</smiles>

Figure 1 and Table II show the effects respectively of temperature and monomer concentration on the polycondensation of DTI with HMD in DMSO. Both the yield and the solution 


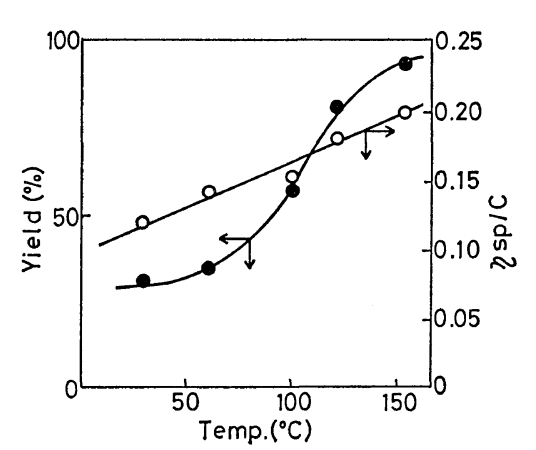

Figure 1. Effect of temperature on the polycondensation of DTI with HMD: monomer concn, $0.25 \mathrm{~mol} / l$ in DMSO, under nitrogen atmosphere; catalyst, EtOLi, $5 \mathrm{~mol} \% / \mathrm{mol}$ of monomer; time, 10 days.

Table II. Effect of monomer concentration on the polycondensation of DTI with HMDa

\begin{tabular}{|c|c|c|c|c|c|}
\hline \multirow[b]{2}{*}{ Atmosphere } & \multirow[b]{2}{*}{$\begin{array}{c}\text { Concn, } \\
\mathrm{mol} / \mathrm{l}\end{array}$} & \multirow[b]{2}{*}{$\begin{array}{c}\text { Time, } \\
\text { day }\end{array}$} & \multicolumn{2}{|c|}{ Yield, \% } & \multirow[b]{2}{*}{$\eta_{\mathrm{sp}} / c^{\mathrm{b}}$} \\
\hline & & & Soluble & $\begin{array}{c}\text { Insolu- } \\
\text { ble }\end{array}$ & \\
\hline \multirow[t]{3}{*}{ Air } & 0.10 & 10 & 35.8 & 6.6 & 0.10 \\
\hline & 0.25 & 10 & 82.6 & 10.7 & 0.23 \\
\hline & 0.50 & 10 & 71.7 & 24.2 & 0.27 \\
\hline \multirow[t]{3}{*}{ Nitrogen } & 0.10 & 10 & 49.5 & 0 & 0.09 \\
\hline & 0.25 & 10 & 75.0 & 0 & 0.17 \\
\hline & 0.50 & 10 & 100 & 0 & 0.22 \\
\hline
\end{tabular}

a In DMSO at $60^{\circ} \mathrm{C}$; catalyst EtOLi, $5 \mathrm{~mol} \%$ l mol of monomer.

b $0.05 \mathrm{~g} / 10 \mathrm{ml}$ in DMSO at $30^{\circ} \mathrm{C}$.

viscosity of resulting polymers increase with increasing monomer concentration and with rising temperature. The polymer having an inherent viscosity of 0.27 was almost quantitatively obtained from a monomer concentration of $0.50 \mathrm{~mol} / \mathrm{l}$ at $60^{\circ} \mathrm{C}$ under air atmosphere. On the other hand, the amount of insoluble polymer increased with increasing monomer concentration, as indicated in Table II.

Since the polycondensation reaction of DTI with HMD is accompanied by the loss of ammonia, it is expected that various acids may have an accelerating effect on the polycondensation, and results are summarized in Table III.

Comparing the viscosities of the resulting polymers with each other, hydrogen chloride has little catalytic effect, as can be seen in Table III. Other acid catalysts either did not have a
Table III. Polycondensation of DTI with HMD in the presence of acid catalysts ${ }^{\mathrm{a}}$

\begin{tabular}{|c|c|c|c|c|}
\hline Catalyst & $\underset{{ }^{\circ} \mathbf{C}}{\text { Temp }}$ & $\begin{array}{c}\text { Time, } \\
\text { day }\end{array}$ & $\begin{array}{c}\text { Yield, } \\
\%\end{array}$ & $\eta_{\mathrm{sp}} / \mathrm{c}^{\mathrm{c}}$ \\
\hline None & 30 & 5 & 32.0 & 0.12 \\
\hline $\mathrm{HCl}$ & 30 & 5 & 37.6 & 0.11 \\
\hline $\mathrm{HCl}$ & 30 & 10 & 43.9 & 0.19 \\
\hline $\mathrm{AlCl}_{3}$ & 30 & 5 & 43.1 & 0.14 \\
\hline$-\mathrm{SO}_{3} \mathrm{H}$ & 30 & 5 & 35.9 & 0.16 \\
\hline None & 60 & 10 & 75.0 & 0.17 \\
\hline $\mathrm{HCl}$ & 60 & 10 & 57.9 & 0.24 \\
\hline $\mathrm{AlCl}_{3}$ & 60 & 10 & 49.3 & 0.15 \\
\hline $\mathrm{SnCl}_{4}$ & 60 & 10 & 50.2 & 0.16 \\
\hline$-\mathrm{SO}_{3} \mathrm{H}$ & 60 & 10 & 54.4 & 0.17 \\
\hline $\mathrm{BF}_{3} \mathrm{Et}_{2} \mathrm{O}$ & 60 & 10 & 44.8 & 0.20 \\
\hline
\end{tabular}

a Monomer concn, $0.25 \mathrm{~mol} / l$ in DMSO, under nitrogen atmosphere.

b Catalyst/Monomer $=1 / 1$ (equivalent).

c $0.05 \mathrm{~g} / 10 \mathrm{~m} l$ in DMSO at $30^{\circ} \mathrm{C}$.

Table IV. Polycondensation of DTI with HMD in PPA or PPE ${ }^{a}$

\begin{tabular}{|c|c|c|c|c|c|c|}
\hline \multicolumn{2}{|c|}{$\begin{array}{l}\text { Monomer, } \\
\times 10^{-3} \mathrm{~mol}\end{array}$} & \multirow{2}{*}{$\underset{\mathrm{g}}{\mathrm{PPA}}$} & \multirow{2}{*}{$\frac{\mathrm{P}_{2} \mathrm{O}_{5}}{\mathrm{~g}}$} & \multirow{2}{*}{$\underset{{ }^{\circ} \mathbf{C}}{\text { Temp, }}$} & \multirow{2}{*}{$\underset{\%}{\text { Yield, }}$} & \multirow{2}{*}{$\eta_{\mathrm{sp}} / c^{b}$} \\
\hline DTI & HMD & & & & & \\
\hline 1 & 1 & 20.0 & 0 & 120 & 36.8 & 0.06 \\
\hline 3 & 3 & 20.0 & 0 & 120 & 64.5 & 0.12 \\
\hline 5 & 5 & 20.0 & 0 & 120 & 88.4 & 0.19 \\
\hline 5 & 5 & 20.0 & 0 & 140 & 92.0 & 0.22 \\
\hline 5 & 5 & 20.0 & 0 & 160 & 94.8 & 0.24 \\
\hline 5 & 5 & 20.0 & 0 & 180 & 90.3 & 0.27 \\
\hline 5 & 5 & 19.0 & 1.0 & 180 & 91.8 & 0.24 \\
\hline 5 & 5 & 18.0 & 2.0 & 180 & 88.2 & 0.26 \\
\hline 5 & 5 & $20.0 *$ & - & 120 & 21.2 & 0.03 \\
\hline 5 & 5 & $20.0 *$ & - & 160 & 29.2 & 0.05 \\
\hline 5 & 5 & $20.0 *$ & - & 180 & 28.5 & 0.05 \\
\hline
\end{tabular}

a Time, $5 \mathrm{hr}$.

b $0.05 \mathrm{~g} / 10 \mathrm{ml}$ in DMSO at $30^{\circ} \mathrm{C}$.

significant effect or had a rather negative influence both on the yield and on the molecular weight of obtained polymers.

Table IV summarizes the results of polycondensation reaction of DTI with HMD in polyphosphoric acid (PPA) or polyphosphate ester (PPE). These are very effective reagents to form esters or amides because of the activation of the carbonyl group.

It is found in Table IV that both the yields 
and the viscosities of the resulting polymers are nearly the same as those of the low temperature solution method. Both the yields and the solution viscosities of the polythioamides obtained in PPA increased with increasing monomer concentration and with rising temperature. No effect was found on the addition of phosphorus pentoxide in PPA. On the other hand, PPE had no effect on the polycondensation reaction of DTI with HMD.

Table $\mathrm{V}$ shows that the result of the polycondensation reaction of DTI with various diamines in DMSO at $60^{\circ} \mathrm{C}$. It is seen that butylenediamine and $m$-xylylenediamine can react with DTI with nearly the same reactivity as HMD, to form high-molecular-weight polythioamides in a good yield. However, the polycondensation reaction of DTI with aromatic diamine such as $m$-phenylenediamine hardly occurred. Table $\mathrm{V}$ also indicates that the polycondensation with secondary diamines such as $N, N^{\prime}$-dimethyl ethylenediamine or piperazine yielded an inferior result to that with HMD. Therefore, the reactivity of diamines with DTI decreased in an order which could be explained by the basicity and the steric effects of the amine.

Table V. Polycondensation of DTI with various diamines in DMSO at $60^{\circ} \mathrm{C}^{\text {a }}$

\begin{tabular}{|c|c|c|c|c|c|c|}
\hline \multirow{2}{*}{ Atmosphere } & \multirow{2}{*}{ Diamine } & \multirow{2}{*}{$\begin{array}{l}\text { Time, } \\
\text { day }\end{array}$} & \multicolumn{2}{|c|}{ Yield, $\%$} & \multirow{2}{*}{$\eta_{\mathrm{sp}} / c^{b}$} & \multirow{2}{*}{$\begin{array}{l}\mathrm{PMT}, \\
{ }^{\circ} \mathrm{C}\end{array}$} \\
\hline & & & Soluble & Insoluble & & \\
\hline \multirow[t]{10}{*}{ Air } & $\mathrm{H}_{2} \mathrm{~N}-\left(\mathrm{CH}_{2}\right)_{2}-\mathrm{NH}_{2}$ & 10 & 37.4 & 1.2 & 0.18 & 118 \\
\hline & $\mathrm{H}_{2} \mathrm{~N}-\left(\mathrm{CH}_{2}\right)_{4}-\mathrm{NH}_{2}$ & 10 & 93.4 & 1.7 & 0.24 & 92 \\
\hline & $\mathrm{H}_{2} \mathrm{~N}-\left(\mathrm{CH}_{2}\right)_{4}-\mathrm{NH}_{2}$ & 50 & 95.8 & 1.9 & 0.24 & 92 \\
\hline & $\mathrm{H}_{2} \mathrm{~N}-\left(\mathrm{CH}_{2}\right)_{6}-\mathrm{NH}_{2}$ & 10 & 71.7 & 24.2 & 0.27 & 125 \\
\hline & $\mathrm{H}_{2} \mathrm{~N}-\left(\mathrm{CH}_{2}\right)_{6}-\mathrm{NH}_{2}$ & 50 & 64.9 & 33.8 & 0.24 & 125 \\
\hline & & 10 & 3.4 & trace & - & 145 \\
\hline & $-\mathrm{CH}_{2} \mathrm{NH}_{2}$ & 10 & 83.9 & trace & 0.22 & 192 \\
\hline & $-\mathrm{CH}_{2} \mathrm{NH}_{2}$ & 50 & 90.3 & trace & 0.25 & 195 \\
\hline & $\begin{array}{l}\mathrm{H}_{3} \mathrm{C} \\
\vdots \\
\mathrm{HN}-(\mathrm{CH}\end{array}$ & 10 & 27.9 & 0 & 0.10 & 115 \\
\hline & HN & 10 & 27.4 & 0 & 0.07 & 86 \\
\hline \multirow[t]{7}{*}{ Nitrogen } & $\mathrm{H}_{2} \mathrm{~N}-\left(\mathrm{CH}_{2}\right)_{2}-\mathrm{NH}_{2}$ & 10 & 31.3 & 0 & 0.14 & 115 \\
\hline & $\mathrm{H}_{2} \mathrm{~N}-\left(\mathrm{CH}_{2}\right)_{4}-\mathrm{NH}_{2}$ & 10 & 91.6 & 0 & 0.24 & 92 \\
\hline & $\mathrm{H}_{2} \mathrm{~N}-\left(\mathrm{CH}_{2}\right)_{6}-\mathrm{NH}_{2}$ & 10 & 100 & 0 & 0.22 & 125 \\
\hline & $\mathrm{H}_{2} \mathrm{~N}-$ & 10 & 5.2 & 0 & - & 145 \\
\hline & $-\mathrm{CH}_{2} \mathrm{NH}_{2}$ & 10 & 89.1 & 0 & 0.23 & 190 \\
\hline & $\begin{array}{c}\mathrm{H}_{3} \mathrm{C} \\
\mathrm{H} \\
\mathrm{H}\end{array}-\left(\mathrm{CH}_{2}\right)_{2}-\stackrel{\mathrm{NH}}{\mathrm{CH}_{3}}$ & 10 & 26.8 & 0 & 0.12 & 112 \\
\hline & $\mathrm{HN}$ NH & 10 & 43.2 & 0 & 0.10 & 85 \\
\hline
\end{tabular}

2 Monomer concn, $0.50 \mathrm{~mol} / l$; catalyst, EtOLi, $5 \mathrm{~mol} \% / \mathrm{mol}$ of monomer.

b $0.05 \mathrm{~g} / 10 \mathrm{~m} l$ in DMSO at $30^{\circ} \mathrm{C}$. 


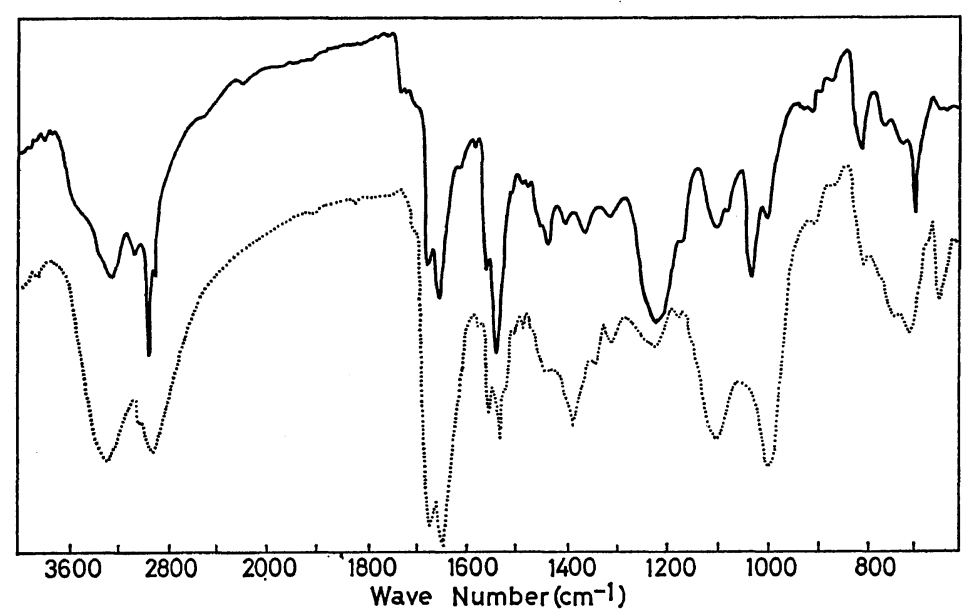

Figure 2. Infrared spectra of polymer of DTI with $\mathrm{HMD}$ ( $\mathrm{KBr}$ disk): $(-)$, soluble polymer; (----), insoluble polymer.

The observed order is as follows

$$
\text { 等, }
$$

On the other hand, the polycondensation reaction of DTI with other nucleophiles such as dihydrazides or diols did not occur at mild conditions. Accordingly, the reactivity of DTI toward nucleophiles is much lower than that of dithioisophthalic acid-O,O-diethyl ester which can react with dihydrazides and diols to form the corresponding polymers, as previously reported. ${ }^{3}$

\section{Polymer Structures}

Infrared spectra of the soluble and insoluble polymers from DTI and HMD are shown in Figure 2. The infrared spectrum of the soluble polymer exhibits the typical absorptions, at 3200 and $1535 \mathrm{~cm}^{-1}$, due to the $\mathrm{N}-\mathrm{H}$ and $>\mathrm{C}=\mathrm{S}$ of thioamide. The insoluble polymer exhibits new absorptions at 1650 and $650 \mathrm{~cm}^{-1}$ which could be attributed to $>\mathrm{C}=\mathrm{N}$ - and $-\mathrm{C}-\mathrm{S}$ - groups. Therefore, the same cross-linking reaction as dis- cussed in a previous paper ${ }^{1}$ might occur.

Linear polythioamide was soluble in DMSO, HMPA or concentrated sulfuric acid and insoluble in benzene or acetone. Insoluble polymers which were precipitated out of the solution during the reaction could not be dissolved in any common organic solvent, suggesting the formation of a highly cross-linked structure. Elementary analyses of polymers were in close agreement with the expected structure.

\section{CONCLUSION}

The polycondensation reaction of dithioamides with diamines took place at relatively mild conditions to form polythioamides with the elimination of ammonia. The reactivity of dithioamides toward nucleophiles was considerably lower than that of dithiocarboxylic acid-O,O-diethyl esters and it was difficult to prepare polythiohydrazides and polythioesters from dihydrazides or diols. However, the reactivity difference between acid amide and thioamide is remarkably great since acid amide does not react with amine at all in a mild reaction condition. The high reactivity of thioamide is presumed to be attributed to the electron-negative character of the sulfur atom which might cause polarization of the thiocarbonyl group to induce easy attacking of nucleophiles. The effect of the sulfur atom on the reactivity of carboxylic acid derivatives with amine is also observed for such compounds as R-CSSR', 
Synthesis of Polythioamides from Dithioamide and Diamine

R-COSR' or R-CSOH about which we will 3. V. E. Shashoua and W. M. Eareckson, J. Polym. be reporting in the near future. Sci., 40, 343 (1959).

\section{REFERENCES}

1. K. Sanui, Y. Kishimoto, and N. Ogata, Polymer J., 2, 789 (1971).

2. Y. Kishimoto, K. Sanui, and N. Ogata, ibid., 4, 18 (1973).

4. W. Pollmann and G. Schramm, Biochim. Biophys. Acta, 80, 1 (1964).

5. E. C. Taylor and J. A. Zoltewigz, J. Amer. Chem. Soc., 82, 2656 (1960).

6. A. E.S. Fairfull, J. L. Lowe, and D. A. Peak, J. Chem. Soc., 742 (1952). 